\title{
CEFALEA CRÓNICA A CAUSA DEL TERCER MOLAR INFERIOR RETENIDO
}

\section{CRONIC HEADACHE RELATED TO THE LOWER THIRD MOLAR RETAINED}

\author{
Neme-Amusquivar L. ${ }^{1 *}$ Morales-Gutierrez L. $^{2}$ \\ ${ }^{1}$ Cirujano dentista. Cirujano Máxilofacial. Docente Instructor Hospital de Clínicas. Docente de cirugía bucal y práctica \\ hospitalaria UMSA.Bolivia. \\ ${ }^{2}$ Licenciada en Odontología, Ortodoncista, Docente de cirugía bucal UNIFRANZ.Bolivia \\ *nememaxilofacial@ hotmail.com
}

\begin{abstract}
Resumen
OBJETIVO.Muchos casos de cefaleas son diagnosticados como idiopáticos, en el presente artículo se presenta el caso de una paciente de sexo femenino de 25 años, que acudió a consultas neurológicas debido a una cefalea crónica constante, de causa desconocida, motivo por lo que la paciente fue remitida a varios especialistas, entre ellas la especialidad de cirugía oral y maxilofacial. En los exámenes complementarios (tomografía) se evidenció el tercer molar inferior retenido en posición invertida, en contacto íntimo con el nervio dentario inferior, atribuyendo a este como causante de la cefalea. Al retirar la pieza dental, se logró eliminar la cefalea.
\end{abstract}

Palabras clave: Diente retenido, cefalea, neuralgia.

\begin{abstract}
OBJECTIVE Many cases of headaches are diagnosed as idiopathic, in this article we present the case of a female patient 25 years old, who attended neurological consultations due to constant chronic headache, of unknown cause, reason why the patient was referred to several specialists, among them the specialty of oral and maxillofacial surgery. In the complementary examinations (tomography), the third lower molar retained in the inverted position was found, with an intimate contact with the inferior dental nerve, attributing this as the cause of the headache. When removing the tooth, it was possible to eliminate the headac.
\end{abstract}

Key words: Held tooth, headache, neuralgia.

\section{INTRODUCCIÓN}

Se denomina dientes retenidos a aquellas piezas dentales que llegada la época normal de erupción, han quedado encerradas dentro de los maxilares, el saco pericoronario permanece íntegro; actualmente se denomina a este fenómeno síndrome de retención dentaria. ${ }^{1,2}$ La importancia de evaluar la retención dental radica en que el diente conserva su saco folicular, cuyo epitelio mantiene la capacidad de diferenciarse lo que podría progresar hacia una lesión tumoral. ${ }^{2}$

Estudios han demostrado que los terceros molares (inferiores y superiores), y los caninos superiores son las piezas con mayor prevalencia de esta patología. Se presentan con mayor frecuencia en los adolescentes y adultos jóvenes, sin tener preferencia de sexo ni raza. ${ }^{1}$ La etiología que interviene en esta patología es multifactorial encontrando factores, locales como: la densidad del hueso que cubre al diente, la falta de espacio en los maxilares poco desarrollados, fibrosis gingival, actualmente falta de desarrollo maxilar por causas de una dieta muy blanda. Factores generales o sistémicos: como el raquitismo, la desnutrición y razones genéticas. ${ }^{1,3}$

Existe una variedad de clasificaciones para la retención de los terceros molares y sus posiciones, como las descritas por Winter, Pell y Gregory; Sandhu y Kaur. Según su posición, la menos prevalente, en las diferentes clasificaciones es la invertida. Con la evolución los seres humanos, han producido cambio en los aspectos filogenéticos, y hábitos alimenticios. Al contrario de lo que sucedía en siglos anteriores, cuando los maxilares eran más utilizados para triturar alimentos más duros; actualmente, los alimentos son menos densos y son más blandos, tornando significativamente un desarrollo anormal de los maxilares, por lo tanto existe una reducción en el tamaño de los mismos y en la cantidad 
de dientes, ocasionando la extinción del cuarto molar y aumentando la incidencia de anodoncia e impactación de los terceros molares. ${ }^{2,4}$

La cefalea puede representar el síntoma nosológico más común en la vida del ser humano. Pese la existencia de estudios científicos aún no se conoce a cabalidad la fisiopatología de este trastorno. La cefalea es un síntoma inespecífico que puede constituir el modo de presentación de diversas patologías intracraneales y sistémicas que requieren tratamiento específico, manifestándose como un malestar intolerable.



Fig. 1. Tomografía evidenciando la posición invertida del tercer molar

Las cefaleas recurrentes más comunes (migrañas y tensionales) no tiene límites precisos. ${ }^{4}$ El nervio trigémino quinto par craneal, tiene su origen en la base del cerebro, con tres ramas que conducen sensaciones de las porciones superior, media e inferior de la cara, y la cavidad bucal. La rama oftálmica o superior aporta sensación a la mayor parte del cuero cabelludo, la frente y la parte frontal de la cabeza. La rama maxilar o media pasa por la mejilla, maxilar superior, labio superior, dientes y encías y alas de la nariz. La rama mandibular, o inferior, recorre por la mandíbula, los dientes, las encías y el labio inferior. Más de una rama nerviosa puede estar afectada por el trastorno. La lesión del $\mathrm{V}$ par craneal puede ser por diversas causas: al ser comprimido por un tumor, traumas, una arteria o una vena inflamada, infecciones y compresión vascular. Esta compresión causa el desgaste del revestimiento protector alrededor del nervio (la vaina de mielina). La neuralgia del trigémino está caracterizada por un dolor punzante intenso y súbito del tipo de shock eléctrico que típicamente se siente de un lado de la mandíbula afectada, acompañada también con dolores intensos en la cabeza. Los ataques de dolor, que generalmente duran varios segundos y pueden repetirse continuamente, vienen y se van a lo largo del día. Estos episodios pueden durar días, semanas, meses, o incluso años. ${ }^{5,6}$

La literatura refiere que el análisis radiológico (radiografía panorámica) es el método de diagnóstico más utilizado en la odontología, ya que revela la presencia de dientes impactados, retenidos o incluidos en la arcada dental, así como otra variedad de patologías de los tejidos óseos y dentales, lo cual es imposible considerar a través del examen clínico de la cavidad bucal. ${ }^{6}$

En la actualidad han existido casos de cefaleas relacionados a dientes retenidos, es por ello que el presente artículo tiene como objetivo es exponer este caso clínico.

\section{PRESENTACIÓN DE CASO}

Paciente de 25 años, de sexo femenino acude a consulta con dolor crónico continuo del lado izquierdo de la cara, y cefalea constante, tras los exámenes complementarios se evidenció un tercer molar retenido en posición invertida. Dada la sintomatología expresada por el paciente, se llegó al diagnóstico de que dicha pieza era causante del dolor de cabeza y de la neuralgia del paciente debido a una compresión del nervio dentario inferior.

\subsection{PROCEDIMIENTO}

Dos días antes de la intervención quirúrgica, se corroboró el factor causante de la cefalea.

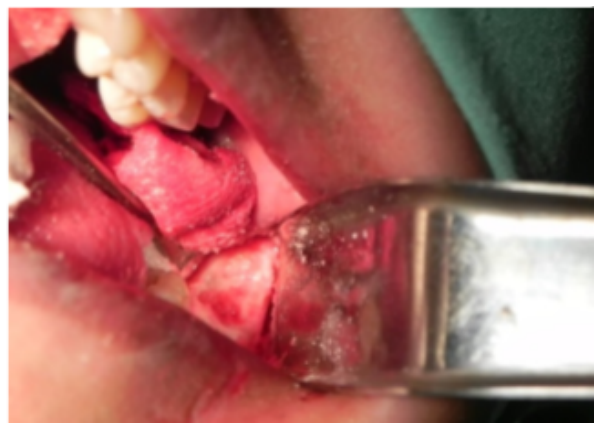

Fig. 2. Incisión lineal festoneada más osteotomía

Para ello se realizó el bloqueo del nervio trigémino con la técnica de spix, una vez anestesiada la paciente, la cefalea disminuyó, este procedimiento fue muy positivo para la paciente y se recomendó la extracción inmediata. Para tal efecto hubo exámenes de laboratorio, los mismos estaban dentro los parámetros normales, también se elaboró un esquema de antibioticoterapia de profilaxis, prescribiendo amoxicilina de 1gr. 3 tabletas 1 hora antes de la intervención y otro gramo pasada las 8 horas después de la intervención quirúrgica.

Se preparó a la paciente para el acto quirúrgico, se realizó la técnica de anestesia, consiguiendo así un bloqueo del nervio, luego se realizó una incisión festoneada lineal, a nivel de la base de la rama continuando hasta el primer molar con bisturí número 11, posteriormente se realizó un fresado exploratorio (Fig.2) al no encontrar la pieza se decidió realizar una ostectomía (Fig.3) para poder crear una fenestración y poder descubrir la pieza.

Este acto se llevó a cabo con la finalidad de no lesionar el segundo molar y proteger el nervio dentario inferior (Fig. 4), 


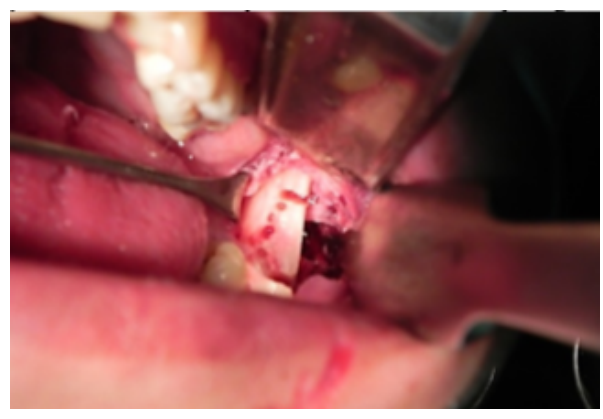

Fig. 3. Incisión lineal festoneada más osteotomía

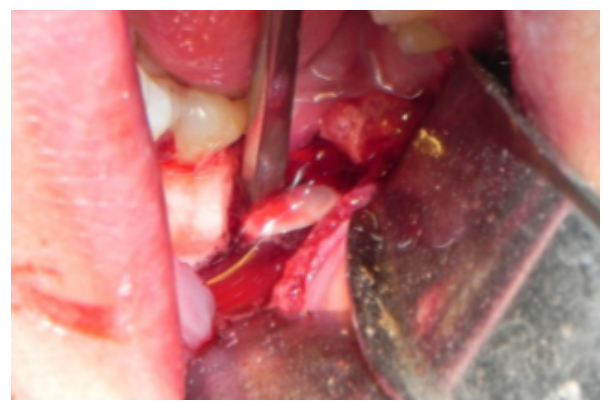

Fig. 4. Fenestración descubriendo parte de la pieza.

descubierta la pieza se procedió a realizar la odontosección por la posición inaccesible del órgano dental, posteriormente se verificó el lecho quirúrgico realizando lavados con solución fisiológica y peróxido de hidrógeno, con la finalidad de retirar cualquier residuo que podía haber quedado (Fig.5). Se retiró el capuchón pericoronario, ( Fig. 6) y se realizó la reposición del colgajo.

El control se llevó a cabo 24 horas después de la cirugía, la paciente se presentó con edema postquirúrgico, y parestesia.

El siguiente control fue después de 7 días, se verificó en la paciente la ausencia del edema y recuperación de la sensibilidad del labio inferior, el dato más relevante referido por la paciente fue la desaparición de la cefalea que presentaba.

\section{DISCUSIÓN}

El presente caso, es una demostración del carácter empírico demostrativo del método científico, dado que se tenía la hipótesis que la etiología de la cefalea era el tercer molar impactado, para ello se procedió a la comprobación de la hipótesis, mediante el bloqueo del nervio con anestesia, lo cual resultó un procedimiento útil para determinar un diagnostico de certeza y de esta manera establecer un correcto plan terapéutico.

Este caso es también una pequeña demostración del carácter holístico de la odontología, pues el paciente es una sola

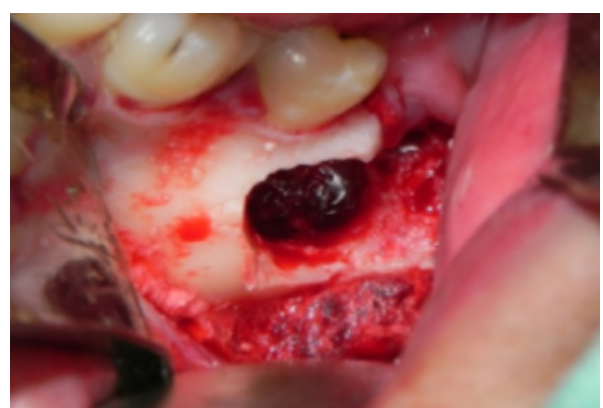

Fig. 5. Extracción de la pieza respetando el segundo molar.

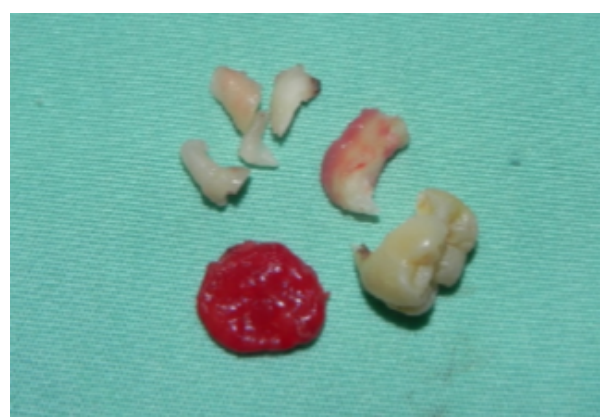

Fig. 6. Tercer molar mas capuchón pericoronario con restos dentarios completos.

unidad y algunas condiciones de la cavidad bucal, pueden tener repercusión en la economía general del cuerpo.

\section{CONCLUSIÓN}

El profesional de salud bucal tiene en sus manos la responsabilidad de entender al paciente como una sola entidad siendo este capaz de correlacionar la sintomatología, exámenes complementarios con la finalidad de emitir un correcto diagnóstico y con ello planificar un plan de tratamento adecuado para mejorar la calidad de vida del afectado.

\section{Conflicto de intereses y financiamiento.-}

Los autores declaran no tener conflicto de intereses, haber cumplido con los requisitos de autoría y haber auto financiado este artículo.

\section{Referencias}

1 Sosa Rosales MC. Guías prácticas de estomatología. Habana. Editorial de ciencias médicas, 2003.

2 Penton Garcia V. Veliz Z. Diente retenido. Cuba. Noviembre, 2009.

3 Adler E. Enfermedades producidas por campos interferentes en terreno del trigémino tomo 1. Colombia,1974. 
4 Koval P. Cefaleas y dolor Cervical. Argentina. Nobiembre, 2011.

5 Hagen N. Stevens J. Trigeminal sensory neuropathy. Rev. Chile 1990.

6 Roberts A. Etiology and treatmed of idiopatic trigeminal and atypical facial neuralgias. Oral. Surgi. 1979.

Recibido: 29 de enero de 2018.

Aceptado: 17 de marzo de 2018. 